\title{
Un cas d'Acuariose du ventricule succenturié, dû à Dispharynx spiralis, chez un pigeon.
}

\author{
Par Christiane COTTELEER
}

Parmi la grande variété de Nématodes infestant les Volailles, les Spirurides sont des Helminthes dont la fréquence est de loin la moins signalée. Sévissant surtout chez les Galliformes et les Ansériformes, la Spirurose du ventricule succenturié des Columbiformes n'a été décrite que très rarement (Nescos, 3 ; Alvez da Cruz et coll., 1 ; Raggi et coll., 4 ; Hwang et coll., 2).

La présence, chez un pigeon, d'un Spiruride de la famille des Acuariidés a été mise en évidence pour la première fois en Belgique, à l'Institut National de Recherches Vétérinaires.

\section{Lésions.}

Provenant des environs de Bruxelles (Hoeilaert), le pigeon dont l'état général était mauvais présentait à l'autopsie de graves lésions du ventricule succenturié. Celui-ci, de consistance molle, était fortement hypertrophié et de nombreux nodules faisaient saillie sur sa face extérieure.

A l'ouverture, un magma caséo-nécrotique s'en échappait ; la muqueuse était tapissée de nodules ulcérés lui donnant un aspect villeux.

Cet amas de détritus ainsi que les nodules renfermaient un gran ${ }^{\circ}$ nombre de vers dont les caractéristiques et mensurations permirent de les identifier comme êtant des Dispharynx spiralis (Molin, 1858).

\section{Morphologie de ces Acuariidés.}

De corps Jlanchâtre, légèrement spiralé et à cuticule finement striée transversalement, ces parasites présentent à la partie antérieure quatre cordons cuticulaires récurrents, fléxueux et non anastomosés. Toujours à la partie antérieure, se distingue une bouche formée de deux petites lèvres latérales se continuant par un vestibule tubulaire ou légèrement en forme de $\checkmark$, long d'environ $100 \mu$ et strié transversalement ; quant à l'xsophage qui lui fait suite, il est nettement partagé en deux parties. 
Le mâle (fig. $1 \mathrm{~B}$ ), plus petit et plus mince, mesure 6,3 à $6,6 \mathrm{~mm}$ de long et 300 à $480 \mu$ de large. La queue, longue de 300 à $345 \mu$, est contournée en spirale. Deux spicules, de forme totalement différente, sont présents : le droit, court et trapu, en forme de barque, mesure 150 à $180 \mu$; le gauche, long et fin, légèrement évasé vers sa partie antérieure, mesure $400 \mu$. On distingue aussi 5 paires de papilles post-anales et 4 paires de papilles pré-anales, ces dernières très rapprochées les unes des autres.

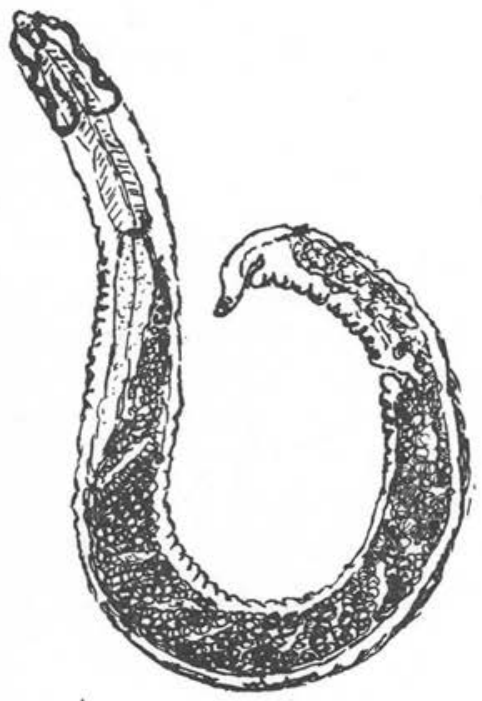

A

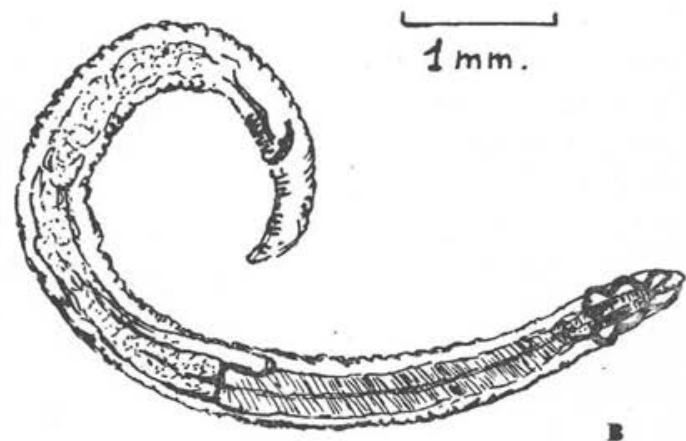

B

FIG. 1. - Dispharynx spiralis. A : femelle ; B : mâle.

La femelle (fig. $1 \mathrm{~A}$ ), plus grande et d'aspect plus massif, mesure 7,20 à $9 \mathrm{~mm}$ de long et 480 à $540 \mu$ de large. La queue, courte, mesure 120 à $160 \mu$; quant à la vulve, située dans la région postérieure du corps, à une distance de $1,8 \mathrm{~mm}$ à $2,3 \mathrm{~mm}$ de l'extrémité caudale, elle est de forme simple et munie d'un ovojecteur court et musculeux. Les œufs, petits et embryonnés, mesurent $40 \mu$ de long et 24 à $28 \mu$ de large.

\section{Bibliographie}

1. Alvez da Cruz, A. et Rodrigues da Costa, A., 1954. - Bol. peeñar, 22, 3/22.

2. Hwang, J. C., Tolgay, N., Shalkop, W. T. et Jaquette D. S., 1961. - Avian Diseases, 5,60 .

3. Nescos, C., 1954. - Ann. Fac. Med. Vet. Pisa, 7, 69/85.

4. RagGi, L. G. et Baker N. F., 1957. - Avian Diseases, 1, 227. 